\title{
Changes in Accumbal and Pallidal pCREB and $\triangle$ FosB in Morphine-Sensitized Rats: Correlations with Receptor-Evoked Electrophysiological Measures in the Ventral Pallidum
}

\author{
John McDaid', Jeanine E Dallimore', Alexander R Mackie' and T Celeste Napier*, \\ 'Department of Pharmacology and Experimental Therapeutics, Loyola University Chicago School of Medicine, Maywood, IL, USA
}

\begin{abstract}
Activation of $\mu$-opioid receptors in the ventral pallidum (VP) is important for the induction of behavioral sensitization to morphine in rats. The present study was designed to ascertain if neurons within the VP demonstrate sensitization at a time when morphine-induced behavioral sensitization occurred (ie 3 or 14 days after five once-daily injections of $10 \mathrm{mg} / \mathrm{kg}$ i.p. morphine) in rats. Western blotting was used to evaluate transcription factors altered by opiates, CREB and $\triangle F$ osB. CREB levels did not change in the VP, but there was a significant decrease in levels of its active, phosphorylated form (PCREB) at both 3 - and I4-days withdrawal. $\Delta$ FosB levels were elevated following a 3-day withdrawal, but returned to normal by 14 days. This profile also was obtained from nucleus accumbens tissue. In a separate group of similarly treated rats, in vivo electrophysiological recordings of VP neuronal responses to microiontophoretically applied ligands were carried out after 14-days withdrawal. The firing rate effects of local applications of morphine were diminished in rats withdrawn from i.p. morphine. Repeated i.p. morphine did not alter GABA-mediated suppression of firing, or the rate enhancing effects of the DI dopamine receptor agonist SKF82958 or glutamate. However, VP neurons from rats withdrawn from repeated i.p. morphine showed a higher propensity to enter a state of depolarization inactivation to locally applied glutamate. Overall, these findings reveal that decreased $\mathrm{PCREB}$ in brain regions such as the VP accompanies persistent behavioral sensitization to morphine and that this biochemical alteration may influence the excitability of neurons in this brain region.

Neuropsychopharmacology (2006) 31, I2I2-1226. doi:I0.1038/sj.npp. I 300854; published online 10 August 2005
\end{abstract}

Keywords: opiates; glutamate; GABA; DI dopamine receptor; addiction; transcription factors

\section{INTRODUCTION}

Systemic administration of moderate doses of morphine to rats produces a biphasic motor response consisting of an initial reduction, followed by increases in motor activity (Babbini and Davis, 1972). Repeated intermittent morphine administration suppresses the initial reduction and robustly enhances the locomotor increase (Babbini and Davis, 1972; Bartoletti et al, 1983). With sufficient number of intermittent treatments, the motor enhancement may progress into stereotypies (Vasko and Domino, 1978; Bartoletti et al, 1983). This enhancement in responding is termed motor, or behavioral, sensitization. The neurobiological underpinnings of behavioral sensitization to drugs of abuse have been proposed to model the brain changes that occur in the human addict (Stewart and Badiani, 1993; Robinson and

\footnotetext{
*Correspondence: Dr TC Napier, Department of Pharmacology and Experimental Therapeutics, Loyola University Chicago School of Medicine, 2I60 South Ist Avenue, Maywood, IL 60I53, USA, Tel: + I 708216 8427, Fax: + I 708216 6596, E-mail: cnapier@lumc.edu Received 9 February 2005; revised 3 June 2005; accepted 29 June 2005 Online publication: 30 June 2005 at http://www.acnp.org/citations/ Npp063005050088/default.pdf
}

Berridge, 1993). Consequently, the biochemical, neuronal, and anatomical substrates of behavioral sensitization have received considerable scientific attention.

The ventral pallidum (VP) exhibits a moderately high expression of opioid transmitter (Maidment et al, 1989) and receptor (Lahti et al, 1989; Olive et al, 1997) proteins. These are part of an opioidergic projection arising in the nucleus accumbens (NAc) (Groenewegen and Russchen, 1984). The NAc to VP projection regulates VP outputs to motor control regions such as the pedunculopontine nucleus and mesencephalic locomotor regions (Swanson et al, 1984; Mogenson and $\mathrm{Wu}, 1986)$. Providing the first evidence for VP involvement in behavioral sensitization, we revealed that intra-VP injection of the $\mu$-opioid receptor antagonist CTOP blocks the development of motor sensitization to systemic morphine (Johnson and Napier, 2000). Behaviors evoked by opiate administration reflect not only actions at opioid receptors but also the action of numerous other transmitters, such as glutamate, GABA, and dopamine (DA), that are under the indirect influence of opioid receptors. It is now clear that motor regulation by these other transmitters occurs at the level of the VP. Locomotion is robustly enhanced by acute intra-VP infusions of agonists to 
$\mu$-opioid (Hoffman et al, 1991; Napier, 1992), DA (Napier and Chrobak, 1992; Gong et al, 1999), and glutamate (Shreve and Uretsky, 1989; Kretschmer, 2000) receptors. VP infusions of GABAergic agonists also readily alter motor function, but the particular response is greatly influenced by the dosing regimen and the ligand used (for a review, see (Napier, 1993)). As a collective, these evidences suggest that neuronal transmission may be modified in the VP with morphine treatment protocols that induce behavioral sensitization. The present study evaluated this possibility by investigating whether or not the function of $\mu$-opioid receptors as well as receptors for DA, GABA, and glutamate are altered in the VP of morphine-sensitized rats.

The effects of activating the receptors of the aforementioned transmitters can converge on several intracellular signal transduction messengers, including cAMP (eg DA D1/D5, $\mathrm{GABA}_{\mathrm{B}}$, and $\mu$-opioid receptors) and $\mathrm{Ca}^{2+}$ (eg glutamatergic receptors). Activation (accomplished via phosphorylation) of a $\mathrm{Ca}^{2+} / \mathrm{cAMP}$ response elementbinding protein (CREB) (Montminy and Bilezikjian, 1987; Gonzalez et al, 1989) initiates expression of genes whose protein products are regulators of transmitter systems engaged by abused drugs (Chrivia et al, 1993). pCREB and CREB levels are altered in various brain regions following exposure to drugs of abuse (Guitart et al, 1992; Turgeon et al, 1997). With regard to opiates, following $24 \mathrm{~h}$ withdrawal from 5 days of continuous morphine exposure (75 mg pellet s.c.), levels of CREB-like immunoreactivity are decreased in the NAc (Widnell et al, 1996). This is in contrast with the effects of the same morphine treatment regimen on levels of CREB in the locus coeruleus and frontal cortex (Widnell et al, 1994) where increases or no change were seen, respectively. Regional differences in basal levels of CREB are of functional importance, for the total amount of available CREB alters the magnitude of the gene expression that is initiated by PCREB (Walters et al, 2003), which in turn alters the nature of the behavioral consequence of repeated exposure to drugs of abuse (Walters and Blendy, 2001).

Members of the Fos family of immediate early genes may be important regulators of consequences of long-term drug treatments. $\Delta$ FosB, a truncated form of FosB, is a peptidaseresistant protein that is persistently upregulated after longterm continuous morphine exposure (Nye and Nestler, 1996). Mutant mice that overexpress $\Delta$ FosB in the striatum demonstrate higher baseline locomotor activity than wild-type controls, and a further motor increase occurs with a repeated cocaine paradigm that induces motor sensitization (Kelz et al, 1999). To date, no pCREB or $\triangle$ FosB assessments have been carried out using morphine treatment paradigms that induce sensitization and VP expression levels have yet to be determined. Given that the NAc (Cadoni and Di Chiara, 1999) and VP (Johnson and Napier, 2000) are implicated in the development of behavioral sensitization to morphine, assessments in these regions are warranted.

To fill these paucities, the present study was designed to ascertain if a repeated morphine treatment regimen that induced an enduring behavioral sensitization also altered levels of pCREB, CREB, and $\triangle$ FosB in the NAc and VP. To further our understanding of the role of VP transmission in this process, neuronal responding to local application of morphine, glutamate, GABA, and the D1 agonist SKF82958 was determined electrophysiologically.

\section{METHODS}

\section{Animals}

Male Sprague-Dawley rats, weighing 280-340 g (Harlan Laboratories Inc., Indianapolis, IN), were housed in pairs in an environmentally controlled vivarium ( $12 \mathrm{~h}$ light/dark cycle; temperature maintained at $23-25^{\circ} \mathrm{C}$ ) with continuous access to standard laboratory rat chow and water. Testing began 1 week after arriving at Loyola Medical Center vivarium. The 'animal use' protocol was approved by the Loyola University Medical Center Institutional Animal Care and Use Committee in accordance with the procedures established in the Guide for the Care and Use of Laboratory Animals (National Research Council, Washington, DC).

\section{Behavioral Assessments}

Treatment phases are diagramed in Figure 1. For all phases, the rats were habituated to the test box for $30 \mathrm{~min}$ prior to the i.p. injection. Ambulations were determined via the number of photobeam breaks as tallied by a computer in $10 \mathrm{~min}$ bins for $90 \mathrm{~min}$. The first phase of acclimation consisted of five to seven once-daily intraperitoneal (i.p.) injections of a saline solution $(1 \mathrm{ml} / \mathrm{kg})$; the last day's motor score was considered the rat's baseline activity level. The second phase, termed repeated treatment, was as follows: 1-3 days after baseline, randomly assigned rats received either five additional once-daily injections of saline or morphine $(10 \mathrm{mg} / \mathrm{ml} / \mathrm{kg}$ i.p. as the sulfate salt in saline; Mallinkrodt, Hazelwood, MO or Sigma Chemical Co., St Louis, MO) and motor activity was obtained as for baseline. After a 3- or 14-day drug-free period, termed withdrawal, all animals were subjected to an acute challenge of morphine $(10 \mathrm{mg} / \mathrm{kg}$ i.p.) and motor activity was again assessed for $90 \mathrm{~min}$. So that all rats would have experienced the test procedure 3 days prior to the acute challenge, those in the 14-day group were reacclimated on withdrawal days 12-13 using the protocol employed for the baseline. Both the initial acclimation prior to repeated treatment and the reacclimation prior to the acute challenge were carried out so that the testing environment was not novel when either repeated treatment or the acute challenge commenced. This ensured that the motor response to either repeated treatment or the acute challenge was not a conditioned response (Johnson and Napier, 2000).

\section{Western Blotting}

Rats were subjected to the same morphine or saline treatment protocols employed for the behavioral assessments, but the injections were conducted in the home cage and motor activity was not assessed (see Figure 1). We have determined that the 5-day acclimation and reacclimation procedures described above resulted in motor scores for rats treated in the test box that were similar to those obtained following home cage injections (unpublished data), thus we conclude that the rats used in the immunoblot studies (as well as the electrophysiological 


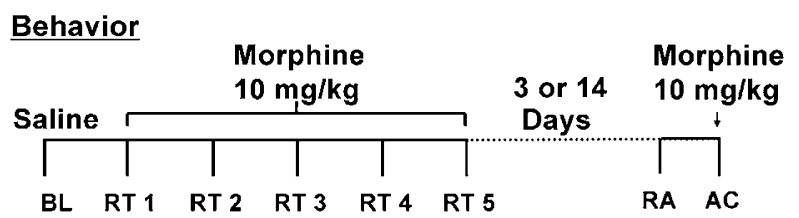

Biochemistry

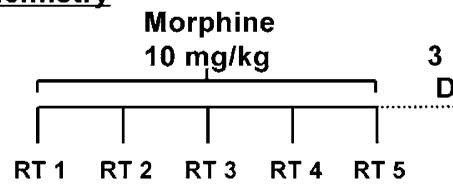

or 14 Days

$\begin{array}{lllll}\text { RT } 1 & \text { RT } 2 & \text { RT } 3 & \text { RT } 4 & \text { RT } 5\end{array}$

Western blotting

Electrophysiology
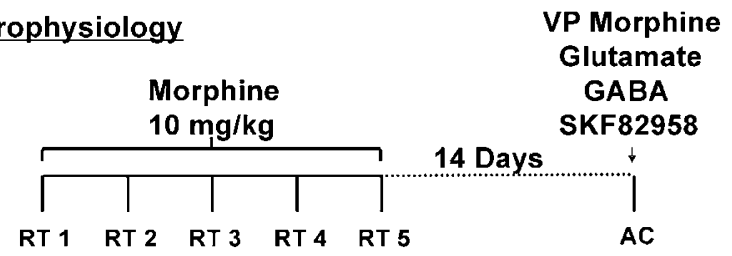

Glutamate GABA

SKF82958 14 Days

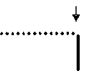

$\begin{array}{lllll}\text { RT } 1 & \text { RT } 2 & \text { RT } 3 & \text { RT } 4 & \text { RT } 5\end{array}$

Figure I Diagrams illustrating the experimental design. The same repeated morphine treatment for behavioral, Western blotting, and electrophysiology experiments. BL, baseline; RTI-5, repeated treatment days; RA, reacclimation (this was performed on days 2 and 13 of the 14-day withdrawal period); $A C$, acute challenge (all AC drugs for the electrophysiology experiments were locally administered using microiontophoresis); VP, ventral pallidum.

experiment, described below) were sensitized to a comparable extent as those tested behaviorally. At 3 or 14 days after the last repeated morphine or saline treatments, the rats were killed by decapitation and their brains were removed and cooled rapidly in ice-cold saline. The NAc and VP were then dissected out, snap frozen on dry ice and stored at $-80^{\circ} \mathrm{C}$. Whole-cell homogenates were prepared by sonication in 20 vol of a homogenization buffer $(25 \mathrm{mM}$ HepesTris $\left(\mathrm{pH} 7.4\right.$ at $\left.25^{\circ} \mathrm{C}\right)$ containing $1 \mathrm{mM}$ EGTA, $1 \mathrm{mM}$ EDTA, $100 \mathrm{nM}$ okadaic acid, $1 \mathrm{mM}$ sodium orthovanadate, and $100 \mu \mathrm{M}$ PMSF). Tissue homogenate protein concentration was determined (protein dye reagent; Bio-Rad, Hercules CA) using the method of Bradford (Bradford, 1976) and $20 \mu \mathrm{g}$ protein samples from individual brain regions were loaded into individual lanes of $4-12 \%$ Bis-Tris gels (Invitrogen, Carlsbad, CA) and were electrophoresed at $165 \mathrm{~V}$ for approximately $1 \mathrm{~h}$. VP and NAc samples were run on separate gels with gel lanes containing samples from either saline-, morphine-, or methamphetamine (results reported elsewhere)-pretreated rats, no tissues were pooled. Two lanes of each gel were used for loading of molecular weight marker proteins (SeeBlue \& MagicMark; Invitrogen, Carlsbad, CA). Proteins were electrophoretically transferred onto a PVDF membrane at $24 \mathrm{~V}$ for $1 \mathrm{~h}$ (using NuPage transfer buffer with $10 \%$ methanol and NuPage antioxidant). Nonspecific protein binding was blocked by incubation at room temperature for $1 \mathrm{~h}$ in blocking buffer (Tris-buffered saline: $25 \mathrm{mM}$ Tris- $\mathrm{HCl}, \mathrm{pH} 7.4,140 \mathrm{mM}$ $\mathrm{NaCl}$ ) containing $0.1 \%$ Tween- 20 and $5 \%$ instant nonfat dry milk. Membranes were incubated overnight at $4{ }^{\circ} \mathrm{C}$ in fresh blocking solution containing the desired primary antibody: 1:2000 rabbit anti-phospho (Ser133) CREB (pCREB), $1: 2000$ rabbit anti-CREB (both from Cell Signaling Technology; Beverly, MA), or 1:2000 rabbit anti-FosB (Santa Cruz Biotechnology; Santa Cruz, CA). After three

washes (20 min each) with TBST (Tris-buffered Saline containing $0.1 \%$ Tween 20 ), the membranes were incubated in a blocking buffer with alkaline-phosphatase-conjugated secondary antibody (1:20000 goat anti-rabbit; Promega, Madison, WI) for $1 \mathrm{~h}$ at room temperature. Following subsequent washes, membranes were treated with a chemiluminescent substrate (ImmunStar; Bio-Rad). To visualize the immunoreactive bands, the membranes were exposed to light-sensitive film (Kodak BioMax light, Eastman Kodak Co., Rochester, NY). Membranes probed for pCREB were reprobed for CREB after stripping (using blot stripping buffer (2\% SDS, $62.5 \mathrm{mM}$ Tris $\mathrm{pH}$ 6.8, with $100 \mathrm{mM} \beta$-Mercaptoethanol) in a shaking water bath for $35 \mathrm{~min}$ at $52.8^{\circ} \mathrm{C}$ ). Quantification of maximum pixel density and molecular weights of each band of interest was carried out using UN-SCAN-IT software (Silk Scientific Corporation, Orem, UT). Optical density of saline bands was averaged and the density of each band on the gel was calculated as a percent of this control. The percent control results from each treatment group were then averaged. Individual pCREB values were also divided by their respective sample CREB values to obtain pCREB/CREB ratio values for each sample and were averaged for each treatment group. All data are the average of two experimental runs. Those values $>2$ standard deviations from the mean were considered to be outliers and not included in the statistical evaluations. Using this criterion, of a total of 47 samples, for $\mathrm{pCREB} / \mathrm{CREB}$, three were omitted from the VP, three from the NAc; for $\triangle$ FosB, two were omitted from the $\mathrm{VP}$ and two from the NAc.

\section{Electrophysiology}

Rats were subjected to the same i.p. morphine or saline treatment protocols employed for the Western blot assessments (see Figure 1). On the 14th day after the repeated treatment regimen, the rats were anesthetized with chloral hydrate $(400 \mathrm{mg} / 2 \mathrm{ml}$ saline/kg, i.p.; Sigma Chemical Co., St. Louis, MO), a lateral tail vein cannula was inserted to allow the intravenous administration of anesthetic supplements. After being placed in a stereotaxic apparatus (David Kopf Instruments, Tujunga, CA) with the nose piece set $3.3 \mathrm{~mm}$ below the horizontal, the skull was exposed and a hole was drilled overlying the VP $(0.3 \mathrm{~mm}$ posterior to bregma and $2.3 \mathrm{~mm}$ lateral to the midline (Paxinos and Watson, 1998)). A thermostatically controlled heating pad (Fintronics, Orange, CT) was used to maintain the core temperature of the rat at $35-37^{\circ} \mathrm{C}$. Experiments were performed during the light cycle and often, more than one cell was recorded per rat.

Extracellular sampling of action potentials and microiontophoretic drug administration were carried out as previously reported from this laboratory (eg Napier et al, 1991; Napier and Maslowski, 1994; Johnson and Napier, 1997b; Turner et al, 2002; Heidenreich et al, 2004). Briefly describing the approach, a glass multibarrel-microelectrode assembly was constructed with the recording microelectrode tip (2-3 $\mu \mathrm{m}$ diameter) protruding $15 \mu \mathrm{m}$ below the tip (12-15 $\mu \mathrm{m}$ diameter) of a five-barreled microiontophoretic pipette. The microelectrode and the center barrel of the iontophoretic pipette were filled with a $0.5 \mathrm{M}$ sodium acetate and $2 \%$ pontamine sky blue solution (BDH Chemicals Ltd, 
Poole, England; in vitro impedance of 4-8 M $\Omega$ and 14$45 \mathrm{M} \Omega$, respectively). The four outer barrels were individually filled with $0.1 \mathrm{M}$ morphine sulfate, $0.1 \mathrm{M}$ glutamic acid, or $0.1 \mathrm{M} \gamma$-amino- $n$-butyric acid (GABA), dissolved in water, or $0.01 \mathrm{M}$ SKF82958 in $0.9 \% \mathrm{NaCl}$ (all 25-110 M $\Omega$ ). Action potential signals were amplified, filtered (200 and $2 \mathrm{kHz}$, half amplitude frequency cutoff) and isolated from the background electrical activity using a window discriminator/amplifier (Fintronics, Orange, CT) while continuously being monitored on a storage oscilloscope (Tektronix, Beaverton, OR). Spiking rate vs time histograms were generated on-line using custom software for a personal computer. Morphine, GABA, and SKF82958 were ejected using cationic currents, glutamate was ejected with an anionic current (drugs were retained in the pipette using a $10 \mathrm{nA}$ current of polarity opposite to the ejection current). Responding to GABA and glutamate, both ionotropic neurotransmitters, was considered to have occurred if at least a $20 \%$ change in spiking was consistently obtained during three trials of ejection at $35 \mathrm{nA}$ for 9 s. For SKF82958 and morphine, both metabotropic drugs, response criteria were at least a $20 \%$ change by a maximum current of $32 \mathrm{nA}$ that was consistent for three two-min ejection periods. Responding neurons were then evaluated using a range of ejection currents. This was accomplished for GABA and glutamate by testing two $9 \mathrm{~s}$ ejection/18 $\mathrm{s}$ retention epochs using $5 \mathrm{nA}$ ejection intervals between 5 and $120 \mathrm{nA}$, or until the maximal response $\left(E_{\max }\right)$ was obtained. For GABA, if zero spikes/s were obtained for three consecutive current increments prior to $120 \mathrm{nA}$, for data analysis purposes, it was assumed that this effect would be maintained for the remaining ejection current increments. For data analysis of GABA-mediated effects, the averaged spikes/s during the two ejections at each nA level was used; glutamate was similarly analyzed, except using the peak spikes/s. Transmitter effects were compared to the spontaneous rate that occurred during each epoch's retention period. Testing for a range of ejection currents for morphine and SKF82958 was carried out by incrementally ejecting the ligand using 1-128 nA of continuous application with each ejection increment lasting $2 \mathrm{~min}$. For data analysis, the last $30 \mathrm{~s}$ of each 2 min ejection current increment was averaged and compared to the last $30 \mathrm{~s}$ of the baseline preceding drug application. Many VP neurons were tested for more than one ligand, but as shown previously (Johnson and Napier, 1997a,b), responding to a given ligand was reproducible with multiple applications and independent of the order of ligand testing (data not shown).

Excessive depolarization induced a decrease in spike amplitude (termed 'depolarization inactivation'; for a discussion, see Turner et al, 2002). To standardize data collection of this phenomenon, the voltage setting of the window discriminator was set to $50 \%$ of the peak spike amplitude such that when this amplitude was decreased below this value as a result of depolarization inactivation, cell spiking was no longer being recorded. The number of VP neurons that went into apparent depolarization block was counted for each ejection current, this allowed for analysis of any treatment-related propensity for VP neurons to go into this inactivated state.

Following the end of the experiment, a reference stereotaxic locale was marked by depositing pontamine sky blue at the tip of the microelectrode. Rats were killed with an overdose of chloral hydrate. The brains were removed, cut into $50 \mu \mathrm{m}$ sections using a microtome/ cryostat (Hacker Instruments, Fairfield, NJ) and floated onto gel-coated slides. The anatomical location of the blue dye deposit was determined on the agreement of at least two people. This site was then used to determine the position of the stereotaxically located recording sites. Data obtained from those recording sites within the VP (Paxinos and Watson, 1998) were analyzed.

\section{Statistics}

All data are illustrated as mean + SEM. Statistical evaluations were performed using Student's $t$-test (electrophysiology and biochemistry), a two-way repeated measures ANOVA with post hoc Newman-Keuls (electrophysiology), a two-way mANOVA (behavior) with post hoc NewmanKeuls, and a Mantel-Haenszel $\chi^{2}$ (electrophysiology) with $p<0.05$. The Western blotting data were analyzed using a two-way mANOVA; this allowed for analysis of two variables (treatment group and withdrawal time) and comparisons between treatment groups at each withdrawal time and also within treatment groups across withdrawal time. Significance was set at $p<0.05$ for all tests. Analyses were carried out using Systat, SigmaStat (Systat Software Inc., Richmond, CA), GB-Stat (Dynamic Microsystems, Silver Spring, MD), and Excel (Microsoft Corporation).

\section{RESULTS}

\section{Behavior}

As illustrated in Figure 2, rats treated once daily with $10 \mathrm{mg} /$ $\mathrm{kg}$ i.p. morphine for 5 days demonstrated enhanced responding to an acute challenge of morphine $(10 \mathrm{mg} / \mathrm{kg}$ i.p.) following 3 or 14 days of drug withdrawal. It is noteworthy that the magnitude of the sensitized response was similar regardless of the withdrawal duration. No somatic signs of morphine withdrawal were noted at either the 3- or 14-day period, which agrees with our previous demonstration that this dosing protocol induces mild somatic withdrawal signs at $24 \mathrm{~h}$ after the fifth injection, but these are dissipated $48 \mathrm{~h}$ later (Johnson and Napier, 2000).

\section{Biochemistry}

Western blot evaluations of the NAc and VP revealed changes in levels of transcription regulator proteins at the same withdrawal periods that an acute morphine challenge induced sensitized behavioral responding (ie either 3- or 14days after 5 once-daily morphine injections). Tissue levels of active form (pCREB) as well as total levels of the transcription regulator CREB were measured. There was an effect of repeated morphine treatment on PCREB levels in both the NAc and VP (Figure 3a). Total CREB was not changed overall (ie an mANOVA did not reveal a repeated treatment effect) (Figure $3 \mathrm{~b}$ ), but at the 3-day withdrawal period there was a significant increase in NAc levels. Consequently, the fraction of active CREB (ie assessed as a pCREB/CREB ratio) showed an overall effect of repeated 


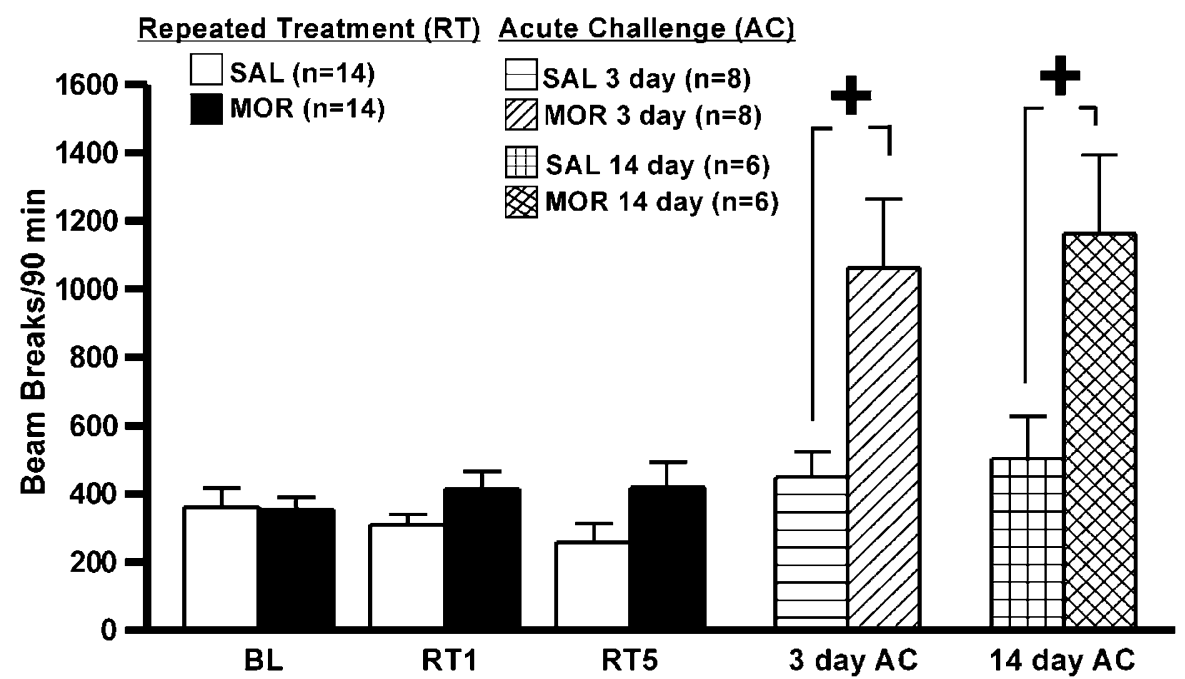

Figure 2 Morphine-induced behavioral sensitization. Presented as an index of motor activity is the number of beam breaks totaled for the 90 min test session. For the acute challenge, a two-way mANOVA revealed a pretreatment effect $(F(I, I 0)=8.04, p=0.017)$, but no effect of withdrawal time or an interaction between the two variables. A post hoc Newman-Keuls test was significant for comparisons between repeated pretreatment groups at each withdrawal period $(+, p<0.05)$. Repeated pretreatment groups: SAL, saline; MOR, morphine. BL, baseline; RTI and RT5, the first and fifth day of repeated treatments; 3 day and 14 day, number of post-RT withdrawal days; AC, acute challenge.

treatment, being reduced in both regions (Figure 3c). These evaluations show that the portion of CREB that is in its activated state is significantly decreased following withdrawal from repeated morphine treatments, and this reduction persists for at least 14 days following the last repeated morphine injection.

Aliquots from the same tissue preparations used to evaluate $\mathrm{pCREB} / \mathrm{CREB}$ were assayed for levels of $\triangle \mathrm{FosB}$ (see Figure 4). $\triangle$ FosB levels were elevated in both the NAc and VP after 3 days. The finding that the elevated levels of $\Delta$ FosB did not endure to 14 days after the repeated morphine injections contrasts the persistence of altered pCREB and behavioral responding to an acute morphine challenge that occurred at this withdrawal time.

\section{Electrophysiology}

The biochemical data revealed a persistent effect of repeated morphine on VP protein levels. Based on these results, we performed electrophysiology experiments at 14 days withdrawal as we were particularly interested in the role of the VP in the persistent expression of behavioral sensitization to morphine. In total, 238 neurons were recorded from within the VP in chloral hydrate-anesthetized rats; ejection current magnitude $v s$ response magnitude relationships were obtained for 93 of these (histologically verified locales are illustrated in Figure 5). The number of neurons sampled in the VP of rats subjected to repeated i.p. pretreatments of morphine $(n=115)$ or saline $(n=123)$ were similar. There was no significant difference between pretreatment groups in any of the action potential characteristics assessed, and the data were therefore pooled. Thus, for the pooled data, $85 \%$ of the recorded action potentials were biphasic, the initial deflection for the action potential was in the negative direction for $73 \%$ and the average action potential peak to peak amplitude was $426 \pm 24 \mu \mathrm{V}$, with a duration of $1.30 \pm 0.03 \mathrm{~ms}$. These action potential characteristics are consistent with prior studies (Mitrovic and Napier, 1996; Turner et al, 2001, 2002) and they suggest that we have been sampling from similar populations of VP neurons. Also similar to prior studies, the spontaneous firing rate for VP neurons recorded from saline-pretreated rats was $15 \pm 1$ spikes/s. A comparable rate was recorded from rats withdrawn from repeated morphine treatments $(16 \pm 1$ spikes/s) revealing that the morphine-treatment regimen did not alter basal firing of VP neurons under the experimental conditions employed here.

Given that there is a tonically active GABAergic innervation of the VP by the NAc that is likely regulated by presynaptic $\mu$-opioidergic receptors (Chrobak and Napier, 1993; Olive et al, 1997), responding to GABA was evaluated for 82 VP neurons (39 from saline- and 43 from morphinerepeatedly treated rats) located throughout the VP (see Figure 6). GABA suppressed firing in 36/39 neurons (92\%) in the saline control group, the rest (3/39 neurons, $8 \%$ ) were not altered. This response distribution was not altered by the repeated morphine pretreatments $\left(\chi^{2}(1)=0.02\right.$, $p=0.89$ ). The magnitude of the response was proportional to the ejection current magnitude until firing completely ceased and the profile of this ejection current $v s$ response was similar for the two repeated pretreatment groups (Figure 6).

D1-like receptor function is altered in the NAc of morphine-pretreated rats (Tjon et al, 1994). Our biochemical data suggest that the effects of repeated morphine in the VP may co-vary with the NAc, we therefore evaluated VP responding to the D1 agonist SKF82958 in rats withdrawn from repeated morphine. A total of 86 neurons were tested with SKF82958 (46 from saline and 40 from morphine treatment groups). Of the neurons from saline-pretreated rats, $28 / 46(61 \%)$ showed an increase in firing rate for the D1 agonist (eg see Figure 7a), while 2/46 (4\%) decreased and the rest $(16 / 46,35 \%)$ were nonresponders. This response distribution is similar to a prior report (Napier 
and Maslowski, 1994) and it was not altered by repeated morphine pretreatments $\left(\chi^{2}(1)=1.05, p=0.30\right)$. The curve profile of the spiking rate $v s$ SKF82958 ejection current magnitude was the same for the two systemic treatment groups (Figure $7 \mathrm{~b}$ ); thus, D1-like receptor function is not altered in the VP 2 weeks after repeated morphine exposure.

Accumbal glutamatergic function is reduced in the NAc following long-term morphine exposure (Martin et al, 1999). We considered that similar alterations might occur in the VP 14 days after repeated morphine treatments. Microiontophoretically applied glutamate increased the

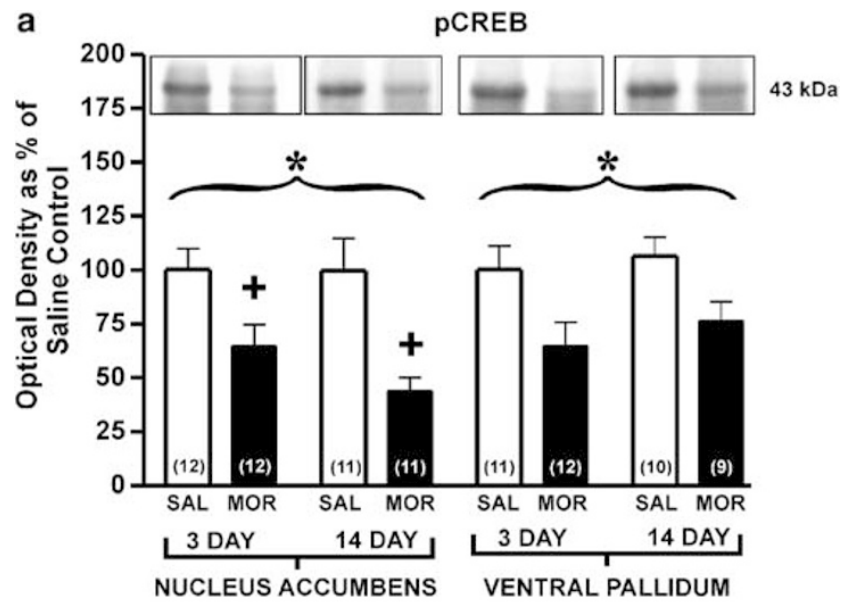

b
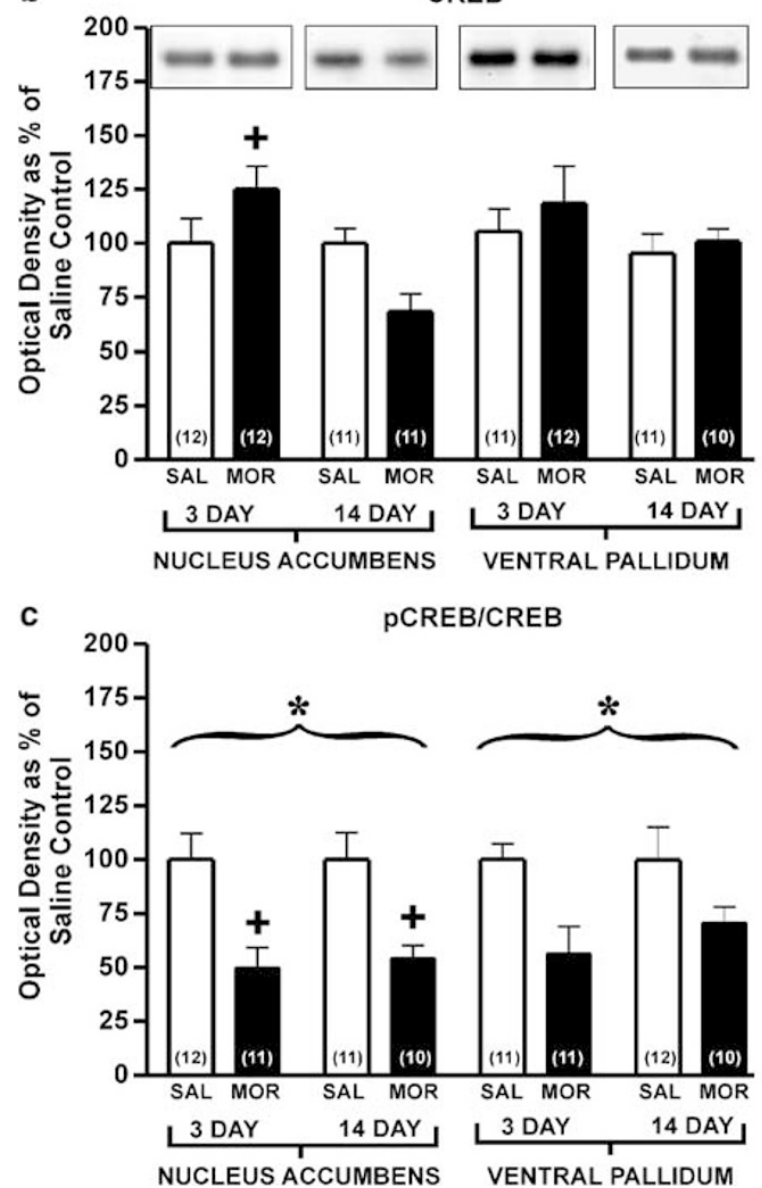

firing rate of $87(80 \%)$ of the 109 neurons tested (54 from saline- and 55 from morphine-pretreated rats; Figure 8), and none exhibited rate decreases. This response distribution was similar between the two repeated treatment groups $\left(\chi^{2}(1)=1.31, p=0.25\right)$. The glutamate ejection current magnitude $v s$ rate enhancement profile also was not altered (Figure 8b). As observed previously for local applications of glutamatergic agonists (Turner et al, 2002), higher ejection currents induced VP responding that exhibited characteristics of excessive depolarization (ie a progressive broadening of the action potential duration and reduction of the amplitude with greater and greater rate increases, until the action potential can no longer be discriminated from the background or spiking is halted), termed depolarization inactivation or block (Bunney and Grace, 1978; Grace and Bunney, 1986). Spiking returned to normal when ejection was terminated. Depolarization inactivation is abrogated by the hyperpolarizing effects of GABA (Grace and Bunney, 1986) and we previously demonstrated in the VP that depolarization inactivation to glutamate agonists is reversed by GABA (Turner et al, 2002). While indicative of excessive transmission, depolarization inactivation may be a physiologically relevant phenomenon for repeated drug treatment (eg neuroleptics (Bunney and Grace, 1978)) and rewardmediated behaviors (You et al, 2001). Thus, it was quantified in the present study (see Methods). As shown in Figure 8c, a Mantel-Haenszel $\chi^{2}$ analysis of the number of neurons entering into this state of inactivation over a number of ejection currents indicated a significant effect $(p=0.03)$ of the repeated morphine pretreatment to increase the propensity of locally applied glutamate to

Figure 3 Repeated morphine treatments decreased the levels of activated (phosphorylated) CREB (pCREB) as well as the ratio of pCREB to CREB in both the NAc and VP. *, indicates a significant overall difference between repeated treatment groups as revealed by two-way mANOVA $(p<0.05)$. + , indicates significance $(p<0.05)$ with post hoc NewmanKeuls between the repeated treatment groups within a given withdrawal period. SAL, repeated treatment with saline; MOR, repeated treatment with morphine. $(a, b)$ The bar graphs are the averaged optical density as $\%$ of saline control. The numbers in parentheses show the sample size. Representative immunoblots are provided above the respective bar graphs. (a) pCREB. For the NAc, there was a repeated treatment effect $(F(I, 20)=15.27, p=0.0009)$ but no withdrawal time or withdrawal timetreatment interaction. For the $\mathrm{VP}$, there was also a repeated treatment effect $(F(I, I 7)=21.68, p=0.0002)$ with no withdrawal time or withdrawal time-treatment interaction. While a post hoc Newman-Keuls revealed no significant differences between repeated treatment groups at either withdrawal time for this brain region, a Student's t-test showed significant differences for each withdrawal time ( $p<0.05$, not illustrated). (b) CREB. For the NAc, there was no repeated treatment effect; however, there was a withdrawal time effect $(F(1,20)=11.90, p=0.0025)$ and a withdrawal time-treatment interaction $(F(1,20)=8.51, p=0.0085$; not illustrated). Although not illustrated, there was also a significant difference between 3 and I4-day withdrawal within the morphine-treatment groups $(p<0.0 \mathrm{I})$. (c) $\mathrm{PCREB} / \mathrm{CREB}$. For the NAc. there was a repeated treatment effect $(F(I, I 9)=22.57, p=0.000 I)$ without a withdrawal time or withdrawal time-treatment interaction. For the VP, there also was a repeated treatment effect $(F(1,2 \mid)=16.49, p=0.006)$ without an effect of withdrawal time, or a withdrawal time-treatment interaction. While a post hoc Newman-Keuls revealed no significant difference for this brain region between treatments at either withdrawal time, a Student's $t$-test showed treatment group differences for each withdrawal time $(p<0.05$; not illustrated). 


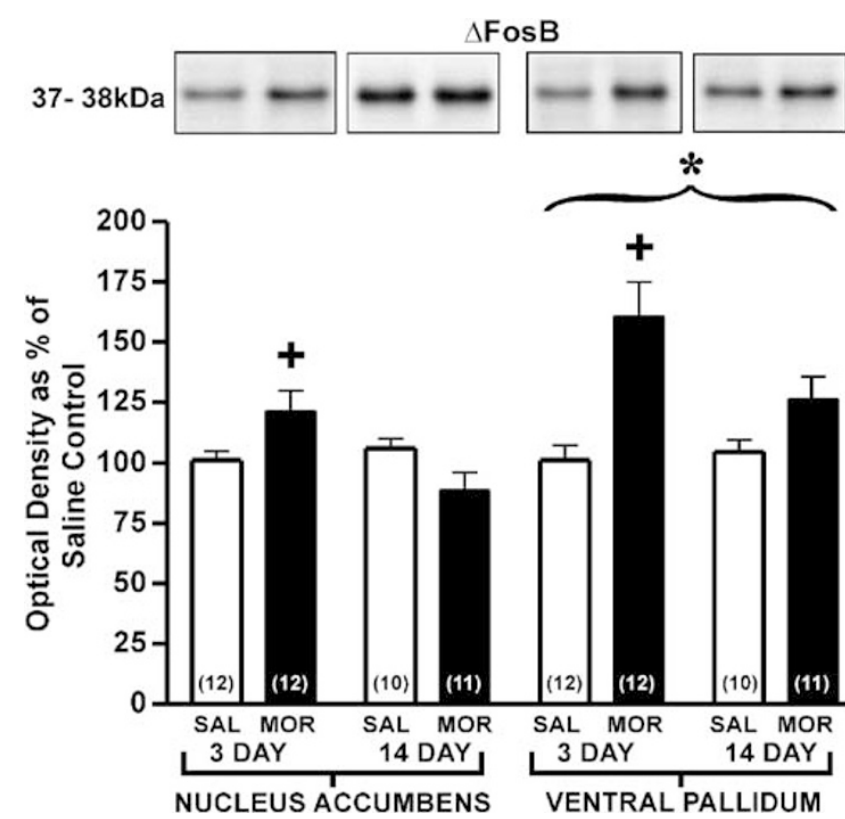

Figure 4 Repeated morphine treatment increased levels of $\triangle F o s B$ in the $\mathrm{VP}$ and NAc. *, indicates a significant overall difference between repeated treatment groups as revealed by two-way mANOVA $(p<0.05) .+$ indicates significance $(p<0.05)$ with post hoc Newman-Keuls between the repeated treatment groups within a given withdrawal period. SAL, saline repeated treatment; $M O R$, morphine repeated treatment. The bar graphs are the averaged optical density as \% saline control. The numbers in parentheses show the sample size. Representative immunoblots are provided above the respective bar graphs. $\triangle$ FosB in the NAc showed no repeated treatment effect but there was a withdrawal time effect $(F(I, \mid 8)=7.04, p=0.016)$ and withdrawal time-repeated treatment interaction $(F(I, I 8)=12.83, p=0.0021$ ) (not illustrated). For ventral pallidal $\triangle F o s B$, there was a significant repeated treatment effect $(F(I, \mid 9)=|8.9|, p=0.003)$, but no withdrawal time and no withdrawal time-treatment interaction. While a Newman-Keuls showed significance between repeated treatment groups within a withdrawal period, for both brain regions there also was a significant difference in $\Delta$ FosB levels between 3 and 14 days withdrawal within the morphine repeated treatment groups $(p<0.05$; not illustrated).

induce apparent depolarization block. These findings suggest that withdrawal from repeated systemic treatments of morphine significantly increased the sensitivity of VP neurons to excessive depolarization mediated by glutamate.

In all, 89 neurons located throughout the VP were tested for responding to iontophoretically applied morphine (44 from the saline- and 45 from morphine-pretreatment groups). Similar to our previous studies in control rats (Johnson and Napier, 1997b), locally applied morphine frequently increased VP spiking rate (Figure 9). Of the 44 neurons tested from the saline-treatment group, iontophoretically applied morphine increased spiking in 38/44 (86.4\%), 1/44 (2.3\%) showed rate suppression, and 5/44 $(11.3 \%)$ were not altered. This response distribution was not altered by the repeated i.p. morphine treatments $\left(\chi^{2}(1)=0.32, p=0.57\right)$. Ejection current-response curves were obtained for 20 of the neurons whose firing was increased by local morphine. The response magnitude was related to the ejection current $(p=0.0001)$ and a post hoc Newman-Keuls revealed that repeated systemic morphine diminished the effect of locally applied morphine on the firing rate of VP neurons at $32 \mathrm{nA}(p<0.01$, Figure 9b).
Higher ejection currents were able to induce an apparent depolarization inactivation. The inactivation profile was similar to that seen with glutamate in the VP and mirrored that previously reported for other brain regions, to iontophoretically applied (Matthews and German, 1984) and intravenously administered morphine (Henry et al, 1992), an effect reversed in both studies by locally applied GABA. As with glutamate iontophoresis, the higher ejection currents (48-128 nA) were assessed by determining the number of neurons that entered into this apparent state of depolarization inactivation for each ejection current increment. In contrast to glutamate, however, Mantel-Haenszel $\chi^{2}$ analysis for response distribution over a number of ejection currents indicated no significant effect of repeated i.p. morphine $(p=0.07)$ to increase the propensity of locally applied morphine to induce depolarization inactivation (Figure 9c).

In summary, these electrophysiological studies revealed that following a 14-day withdrawal, repeated morphine treatment did not change the rate diminishing effects of locally applied GABA or the rate enhancing effects of the D1 agonist SKF82958 in the VP. However, repeated i.p. morphine increased the propensity of VP neurons to enter into a state of apparent depolarization block with local glutamate application when compared with VP neurons from saline-pretreated rats. In contrast, repeated morphine pretreatments did not alter the propensity of VP neurons to go into depolarization block with locally applied morphine; indeed, the excitatory effect of this ligand was actually decreased in morphine-pretreated rats.

\section{DISCUSSION}

The results show that after the dissipation of any acute somatic withdrawal symptoms from five daily injections of a moderate morphine dose, and at post-treatment withdrawal times when behavioral sensitization could be evoked by an acute morphine challenge, there were withdrawal time ( 3 vs 14 days) and brain region (NAc vs VP) differences in several indices of neuronal plasticity. The time- and regiondependent effects were specific to particular transcription factors. Particularly novel are the findings that the VP shows persistent alterations, assessed functionally at the neuronal level, that were transmitter-system specific. This divergence of responding aids in ascertaining the cellular mechanisms that accompany morphine-induced behavioral sensitization.

We revealed that repeated intermittent exposure to morphine significantly altered NAc and VP brain levels of $\Delta$ FosB. This concurs with a prior report of $\Delta$ FosB increases in NAc following repeated daily injections of cocaine (Nye et al, 1995). We determined, however, that $\Delta$ FosB expression was elevated at a time when tissue levels of pCREB (or the pCREB/CREB ratio) were decreased. pCREB is thought to enhance $\Delta \mathrm{FosB}$ expression (Andersson et al, 2001). If this cascade applies to the brain regions assayed, the divergence in tissue levels at the 3-day withdrawal period may reflect temporal differences in the drug-induced effects on pCREB and $\triangle$ FosB. CREB is activated (phosphorylated) very rapidly after a single stimulus or acute drug treatment (Konradi et al, 1994). This can increase $\Delta$ FosB (Andersson et al, 

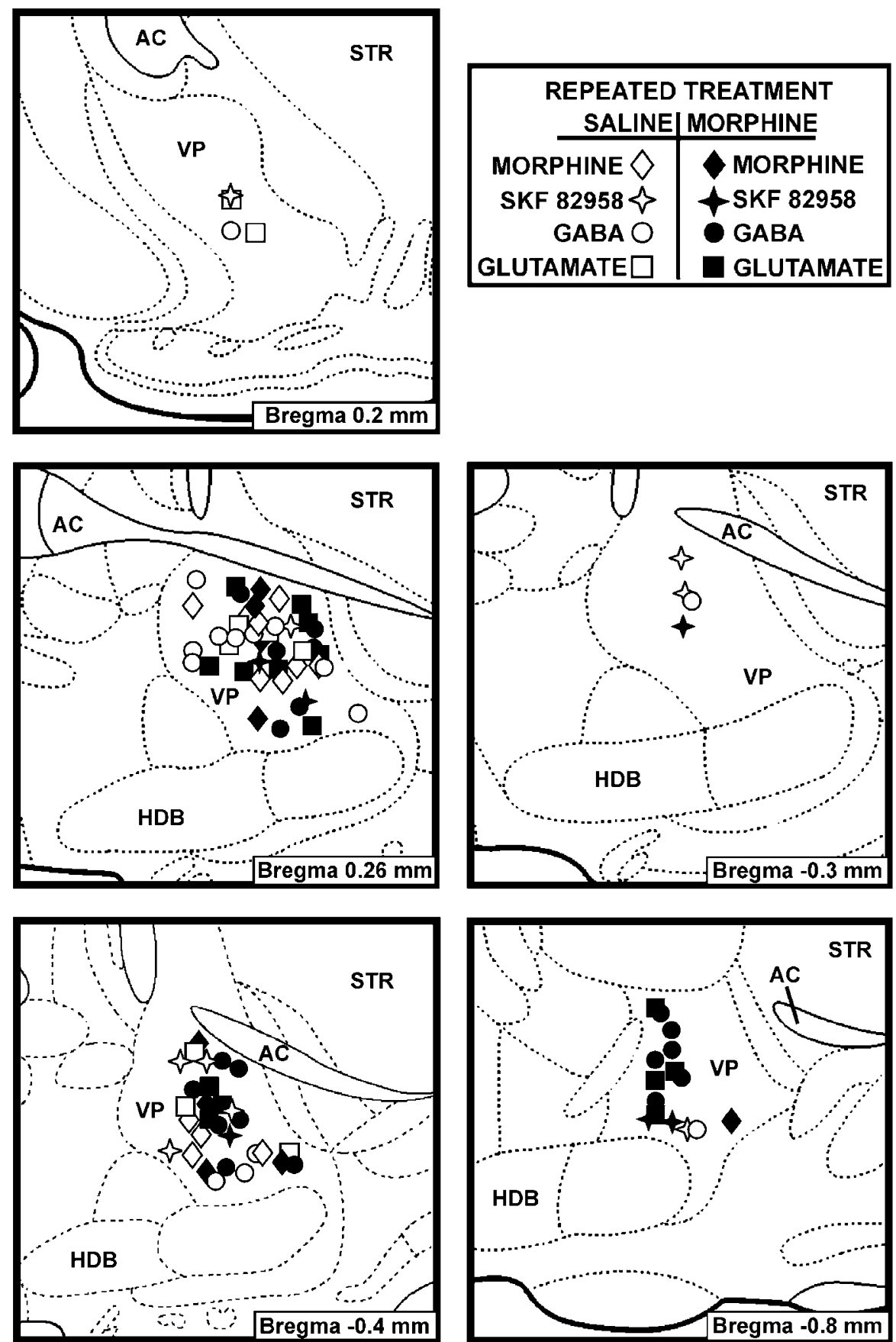

Figure 5 Illustration of the anatomical location of electrophysiologically recorded ventral pallidal neurons used in the microiontophoresis ejection currentresponse curves. Locations are categorized according to the iontophoretically applied ligand (ie $\boldsymbol{\bullet}, \boldsymbol{\bullet}$, etc.), thus, most neuronal recordings are represented more than once. Shaded symbols represent the stereotaxic locale of neurons recorded from rats withdrawn from repeated morphine treatments ( $10 \mathrm{mg} / \mathrm{kg}$, i.p.), whereas open symbols represent the locale of neurons recorded from saline control rats. Indicated in the lower right region of each panel is the anterior/posterior location from bregma (Paxinos and Watson, 1998). AC, anterior commissure; STR, striatum; VP, ventral pallidum; HDB, nucleus of the horizontal limb of the diagonal band.

2001), and with repeated stimuli (eg repeated morphine injections used in the present study), $\Delta$ FosB, an exquisitely stable protein, accumulates in brain tissue (McClung et al, 2004). The decreases in tissue pCREB may be a 'rebound' adaptation to its repeated elevation during treatment (see below for further discussion). Thus, the increased levels of $\triangle$ FosB observed in this study may be the result of increased CREB transcriptional activity during the repeated treat- ment, but only the elevated $\Delta$ FosB effect persisted to 3 days after treatment termination. $\Delta$ FosB levels returned to normal by the 14-day withdrawal period. This likely reflects the fact that while this protein is long lasting, without repeated or sustained stimuli, its levels eventually return to normal (McClung et al, 2004). As motor sensitization occurred at the 14-day withdrawal time, when $\Delta$ FosB levels were no longer elevated, it may be that transcriptional 


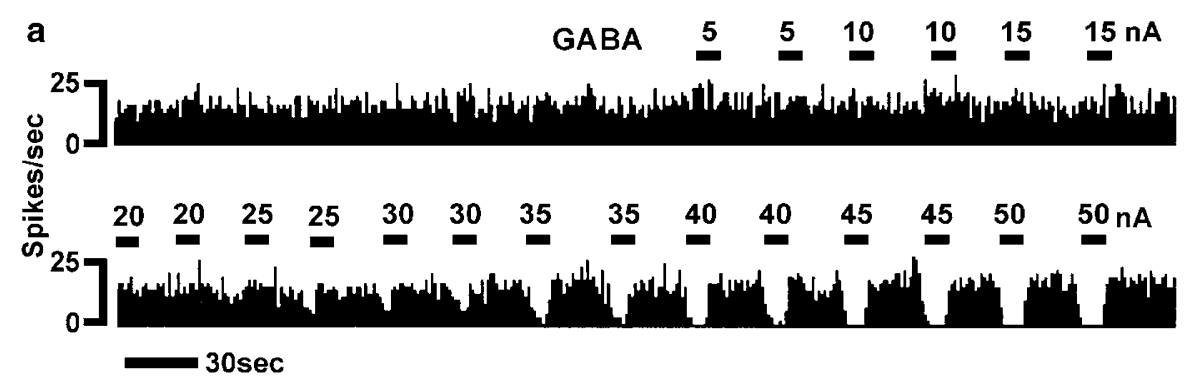

b

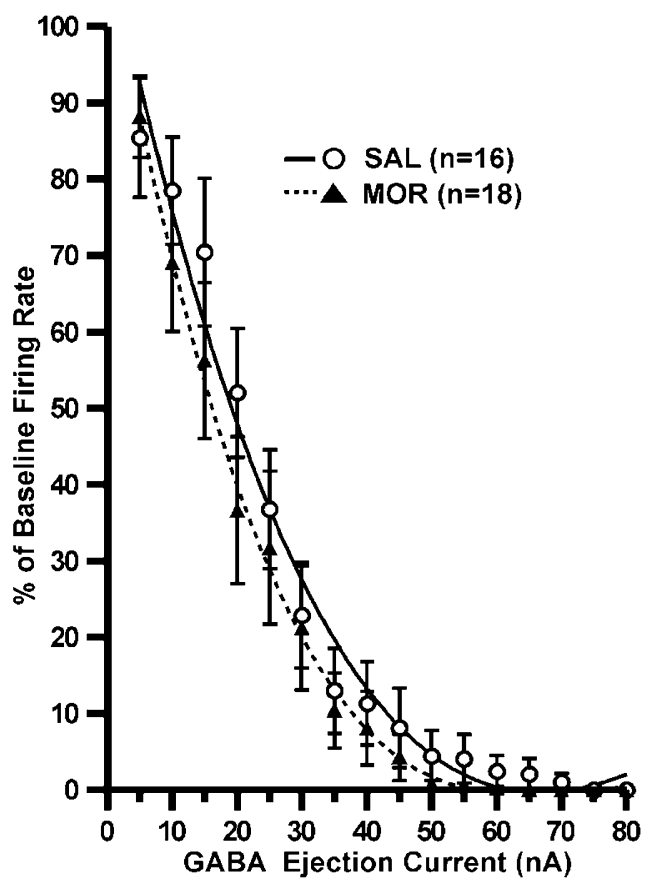

Figure 6 GABA-induced inhibition of neuronal firing was not altered by repeated i.p. morphine treatments. (a) Real-time histogram separated into two panels illustrating the effect of GABA on the firing rate of a neuron from the VP of a saline-treated rat. Dashes above histogram illustrate ejection periods and the numbers illustrate the ejection current magnitude. (b) Averaged rate effects of iontophoretically applied GABA from ventral pallidal neurons recorded 14 days after the rats received repeated i.p. treatments of saline ( $\mathrm{SAL}$; open symbols) or morphine (MOR; closed symbols). A two-way repeated measures ANOVA revealed an effect of ejection current magnitude $(F(I I, 34 I)=70.99, p<0.000 I)$ but no difference between repeated i.p. pretreatments, or ejection current-pretreatment interaction.

consequences of the 3-day elevation in $\Delta$ FosB endured up to 14 days.

Decreased pCREB has been implicated in the persistence of behavioral sensitization to cocaine (Walters and Blendy, 2001) and pCREB-deficient mice display an enhanced behavioral response to acute morphine (Walters et al, 2005). These reports, together with our results, indicate that decreased PCREB may play a role in behavioral sensitization to morphine. Comparing the levels of pCREB with its unactivated form, CREB, provided cues as to biochemical mechanisms that are involved, and underscored regional differences in this process. CREB remained unchanged in the VP, but in the NAc, CREB levels were increased at 3 days of withdrawal and decreased at 14 days. As pCREB was decreased at both withdrawal periods, accumbal levels of the activated form appear to be independent of the expression levels of its inactive substrate. These results are indicative of a stronger role of protein kinase activity on levels of pCREB, as compared to the total amount of CREB that is available to be phosphorylated. Future studies on the role of kinases that are involved in maintenance of the basal phosphorylation state of CREB, such as $\mathrm{Ca}^{2+}$ /calmodulindependent kinase IV (CAMKIV) (Ho et al, 2000), would aid in determining the merit of this possibility.

As consequences of $\mu$-opioid receptor activation and pCREB-mediated signaling may reflect an alteration in receptor-mediated transmission, we electrophysiologically determined if several receptor systems were functionally changed in the VP 14 days after repeated i.p. morphine. The ability of GABA, or the D1-like DA agonist SKF82958 to regulate VP spiking rate was not altered, suggesting that these VP receptors did not underlie the enhanced motor responding that occurred with an acute morphine challenge. This finding contrasts prior assessments of these transmitter systems in the NAc following chronic continuous morphine treatment $(75 \mathrm{mg}$ pellets s.c. for 5 days) which revealed an increased GABAergic transmission in the VTA (Bonci and Williams, 1997) and enhancements in D1receptor signaling cascade in striatal neurons (Chartoff et al, 2003). It remains unclear if the reason for the 
a

SKF82958 nA

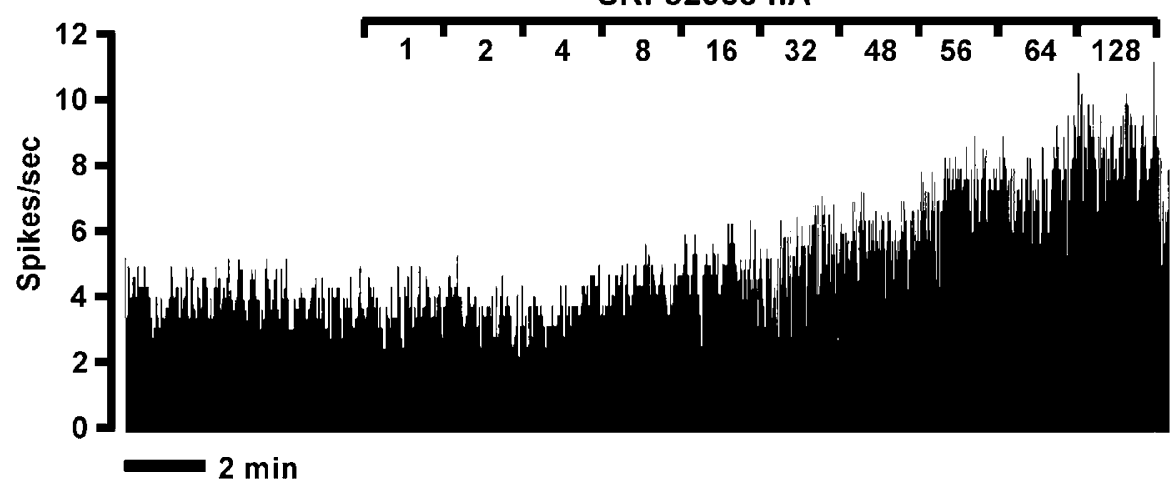

b

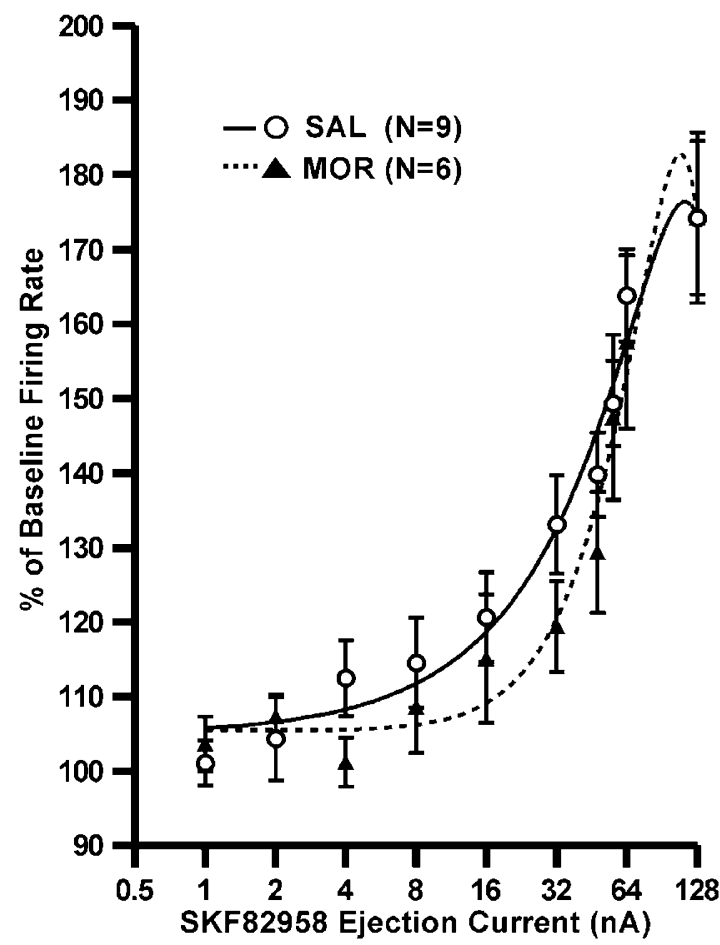

Figure 7 The rate enhancing effect of the DI agonist SKF82958 was not altered by repeated i.p. treatments of morphine. (a) A real-time histogram illustrating the firing rate increases evoked by iontophoresing SKF82958 on a single ventral pallidal neuron of a morphine-treated rat (scale above histogram illustrates the beginning of SKF82958 ejection and nA magnitude of ejection currents). (b) The averaged rate enhancing effect of iontophoretically applied SKF82958 in ventral pallidal neurons recorded 14 days after repeated i.p. treatments of saline (SAL; open symbols) or morphine (MOR; closed symbols). A two-way repeated measures ANOVA revealed no repeated i.p. pretreatment effect or ejection current-pretreatment interaction, but did reveal an ejection current effect $(F(9,72)=12.98, p<0.000 I)$

differences between the current results and this literature reflect differences in the adaptive properties of the various brain regions and/or repeated intermittent (ie sensitizing) treatments $v s$ chronic exposure. Both possibilities are worthy of future studies.

Assessing the consequences of repeated morphine pretreatments on pallidal glutamatergic function revealed that while the rate enhancing effects remained intact, there was a greater propensity of higher synaptic concentrations of glutamate to induce depolarization inactivation. If the VP adapts like other brain regions following repeated or sustained morphine exposure, this response may reflect increased basal $\mathrm{Ca}^{2+}$ levels (Narita et al, 2002) or a decreased $\mathrm{Ca}^{2+}$ buffering capacity (Garcia et al, 1996). Calbindin is a $\mathrm{Ca}^{2+}$ buffering protein that is expressed in high levels in the VP (Zahm et al, 2003) and this protein is decreased in the brains of CAMKIV knockout mice that are deficient in pCREB (Ribar et al, 2000). As pCREB was reduced in the VP with the same morphine treatment regimen that altered glutamatergic function, it may be that a decrease in VP levels of $\mathrm{Ca}^{2+}$-buffering proteins, such as calbindin, underlies the enhanced depolarization inactivation effect of glutamate in this region. In addition to a possible involvement of general $\mathrm{Ca}^{2+}$ mechanisms, this effect of glutamate likely reflected receptor-selective events, for the excitatory actions of SKF82958 did not result in depolarization block, and the capacity of morphine to produce depolarization block was not changed in rats repeatedly treated with the opiate. Repeated systemic administration of heroin increases glutamate and decreases 
a
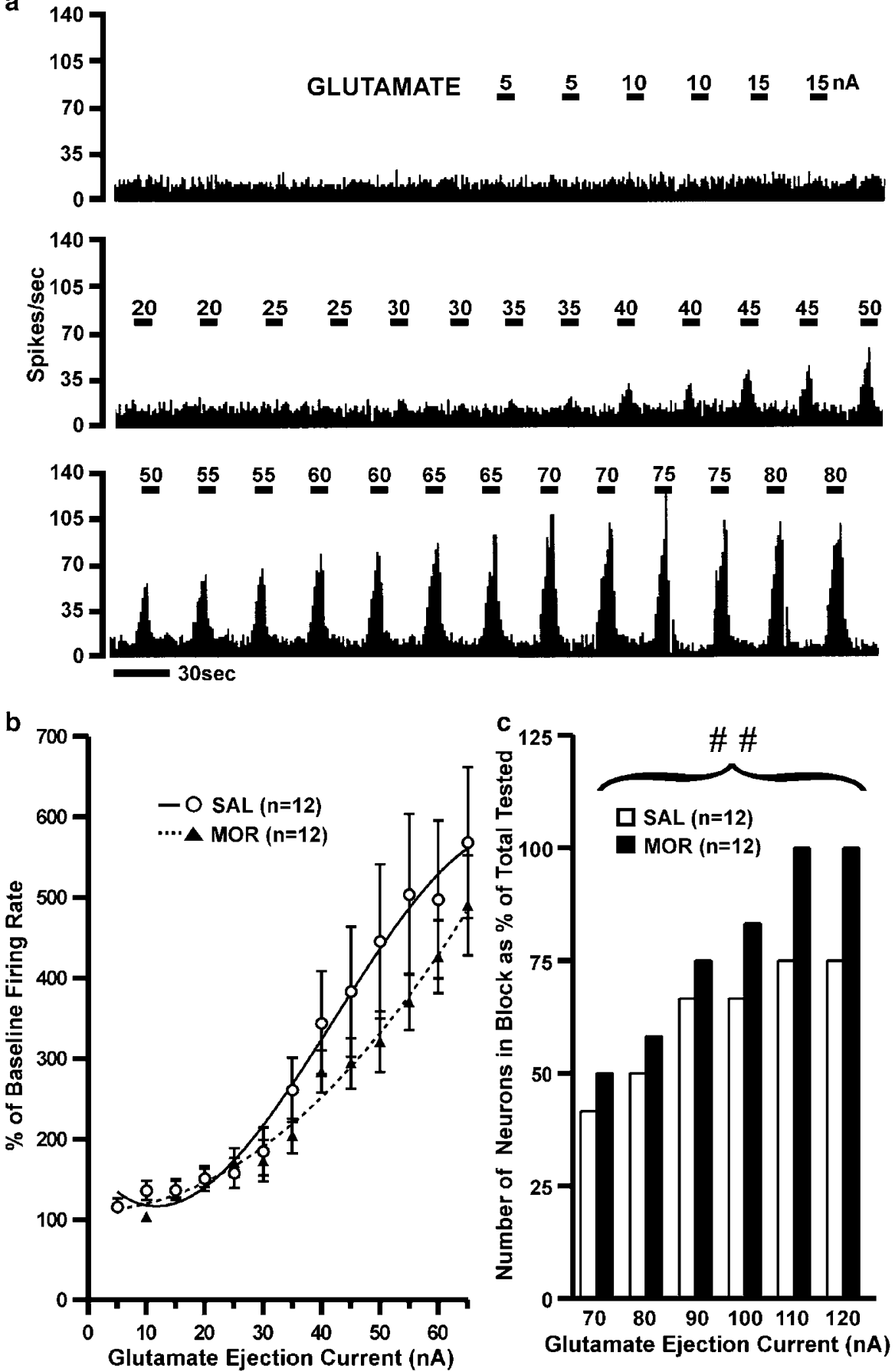

Figure 8 The rate enhancing effect of glutamate was not changed following 14 days of withdrawal from repeated i.p. morphine treatments, but the ability of glutamate to promote depolarization inactivation was significantly increased. (a) Real-time histogram separated into three panels illustrating the effect of microiontophoretically applied glutamate on the firing rate of a single ventral pallidal neuron of a saline-pretreated rat. Dashes above histogram illustrate ejection periods and the numbers provide the ejection current magnitude. (b) Line chart showing the averaged rate enhancing effects of iontophoretically applied glutamate in ventral pallidal neurons recorded 14 days after repeated i.p. treatments of saline (SAL; open symbols) or morphine (MOR; closed symbols) (graphed as \% of baseline firing rate). A two-way repeated measures ANOVA revealed an ejection current effect $(F(I 5, \mid 80)=9.88, p<0.000 \mid$ ) with no repeated i.p. pretreatment or ejection current-pretreatment interaction effect. (c) Cumulative \% of neurons that exhibited depolarization inactivation at each respective nA ejection current. Data were calculated as the number of neurons that exhibited depolarization inactivation (see Methods) at each nA ejection current as a \% of the total number of neurons in the ejection current-response curve. \#\#, indicates significance, a Mantel-Haenszel $\chi^{2}$ analysis for response distribution $\left(\chi^{2}=4.91, p=0.03\right)$ revealed an effect of the repeated i.p. morphine pretreatments on the propensity of neurons to go into depolarization block. Repeated i.p. pretreatment groups: SAL, saline (open symbols/bars); MOR, morphine (closed symbols/bars).

GABA levels in the VP of rats (Caille and Parsons, 2004). Thus, it may be that glutamatergic transmission is being promoted in opiate-sensitized rats at a time when a tonic
GABAergic-induced inhibition is reduced and the capacity to buffer the intracellular consequences of excessive glutamatergic transmission is compromised in the VP. 
a

MORPHINE nA
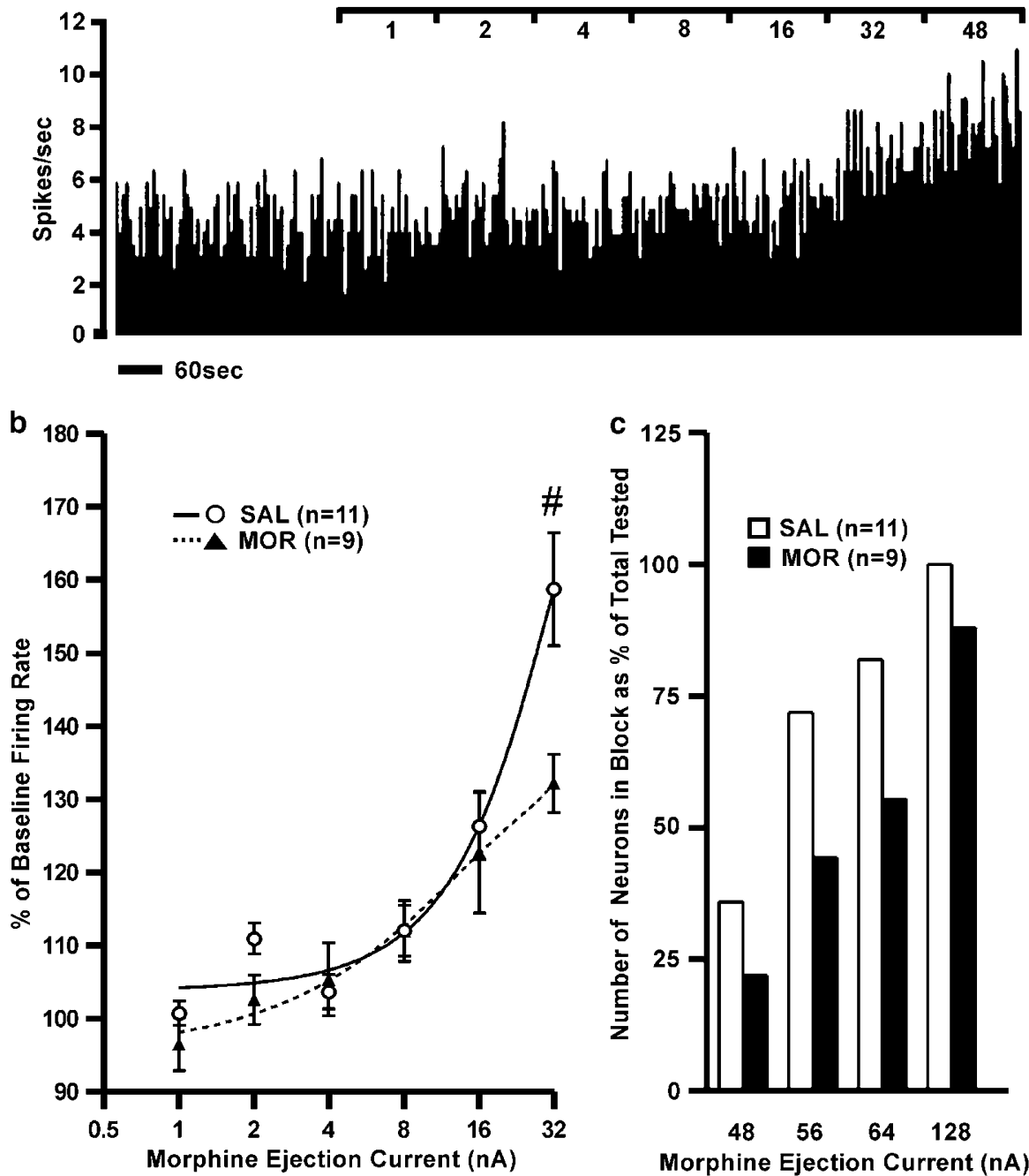

Figure 9 The rate enhancing effect of locally applied morphine is significantly decreased after I 4 days withdrawal from repeated morphine treatments, but the propensity for VP neurons to go into depolarization block is unchanged. (a) A real-time histogram illustrating the rate enhancing effects of morphine on a single ventral pallidal neuron of a morphine-pretreated rat. Scale above histogram illustrates beginning of morphine ejection and nA magnitude of ejection currents. (b) The averaged rate enhancing effect of iontophoretically applied morphine in ventral pallidal neurons recorded I4 days after repeated i.p. treatments of saline (SAL; open symbols) or morphine (MOR; closed symbols). A two-way repeated measures ANOVA revealed no pretreatment effect or ejection current-pretreatment interaction but did reveal an ejection current effect $(F(7,84)=29.99, p=0.000 \mathrm{I})$ and a post hoc Newman-Keuls revealed that morphine pretreatment diminished the effect of locally applied morphine on the firing rate of VP neurons at $32 \mathrm{nA}$ (\#, $p<0.0$ I). (c) Cumulative \% of neurons that exhibited depolarization inactivation at each respective $\mathrm{nA}$ ejection current. Data were calculated as the number of neurons that exhibited depolarization inactivation (see Methods) at each nA ejection current as a \% of the total number of neurons in the ejection current-response curve. All but one of the neurons was inactivated before the maximum ejection current was reached. A Mantel-Haenszel $\chi^{2}$ analysis for response distribution over a number of ejection currents indicated no significant effect of repeated i.p. morphine $\left(\chi^{2}=3.23, p=0.07\right)$ to alter the propensity of locally applied morphine to induce depolarization inactivation. Repeated i.p. pretreatment groups: SAL, saline (open symbols/bars); MOR, morphine (closed symbols/bars).

The combined effects may be increased frequency of neuronal inactivation during those periods of elevated glutamatergic drive.

Also tested was the possibility that the function of $\mu$ opioid receptors, the primary target of morphine, may differ in the VP between rats repeatedly treated with saline $v s$ morphine. In saline-pretreated controls, locally applied morphine increased firing in the majority of responding VP neurons, replicating our prior report of the phenomenon (Johnson and Napier, 1997b). As activation of $\mu$-opioid receptors is known to increase $\mathrm{K}^{+}$, and decrease $\mathrm{Ca}^{2+}$ conductance (Wimpey and Chavkin, 1991; Rhim and Miller,
1994), both of which would act to suppress spiking, morphine-induced rate increases likely reflect indirect mechanisms (for a review, see North, 1993). In the VP, $\mu$-opioid receptors are located on soma and fibers within the VP, with a major presynaptic distribution (Olive et al, 1997). Microiontophoresis deposits ligands within a few micrometers of the pipette tip (Hicks, 1984), which can influence both pre- and postsynaptic elements. Microiontophoretically applied morphine within the VP can attenuate the effects of several transmitters including GABA (Chrobak and Napier, 1993; Johnson and Napier, 1997b) which may reflect activation of presynaptic $\mu$-opioid receptors on 
GABAergic terminals. Since the GABAergic input to the VP is tonically active in chloral hydrate-anesthetized rats (Chrobak and Napier, 1993; Turner et al, 2002), it is likely that $\mu$-opioid receptor-mediated inhibition of GABA release underlies the acute excitatory responses to local morphine applications in the VP.

Repeated systemic treatments with morphine followed by 14 days of withdrawal resulted in a decrease in the maximal excitatory effect obtained in VP neurons with microiontophoretic applications of morphine. This result could reflect a decrease in the capacity of acute, locally applied morphine to presynaptically modulate other transmitters via compensatory changes in number, or efficiency, of the presynaptic $\mu$-opioid receptor. While data regarding changes in $\mu$-opioid receptor density in the brains of morphinesensitized animals are inconclusive, reports on $\mu$-opioid receptor-regulated signal transduction provide a more compelling explanation of the current findings. A second messenger involved in this process is cAMP. Acute activation of the $\mu$-opioid receptor decreases cAMP activity (Wang and Gintzler, 1994) leading to a decrease in presynaptic GABAergic transmission (Bonci and Williams, 1997). $\mu$-Opioid receptor-induced decreases in cAMP are attenuated in the striatum in morphine-sensitized rats (Vigano et al, 2003). A similar 'blunting effect' may occur in the VP. This would reduce the ability of locally applied morphine to presynaptically inhibit GABA, and thus decrease VP GABA concentration similar to that reported for the VP in rats repeatedly exposed to heroin (Caille and Parsons, 2004). These adaptations could lead to the downward shift in the maximal rate enhancing response to morphine observed in the present study. The observation that VP neurons did not display the same increased propensity to go into depolarization block to locally applied morphine as was seen with glutamate may relate to the difference in the mode of action for these two ligands in morphine-sensitized rats. That is, the direct activation of glutamate receptor channels to profoundly depolarize neurons would not be mimicked by the indirectly mediated rate enhancements that result from a $\mu$-opioid receptorinduced disinhibition of GABA release. It is noteworthy that the downstream effect of reduced GABA release is not changed by morphine-induced sensitization. This conclusion is drawn from the lack of a change in sensitized rats to the rate altering effects of exogenously (microiontophoretically) applied GABA, which, by acting at postsynaptic sites, can override presynaptic modulation of endogenous transmitter. These findings underscore the possibility that GABA transmission is altered by morphine-induced sensitization; it likely occurs at presynaptic terminals.

In conclusion, the results presented in this report reveal that at 14 days following repeated systemic treatments of morphine, when behavioral sensitization is obtained in response to an acute morphine challenge, the VP shows significant decreases in PCREB, increases in the detrimental effects of elevated glutamate, and diminished responding to local applications of morphine. These observations reveal that the VP demonstrates enduring neuronal alterations induced by repeated morphine. This effect was selective in so far as no changes were observed in $\triangle$ FosB levels or in responding to GABA or the D1 agonists SKF82958 at the 14day withdrawal period. Decreased pCREB levels may be a reflection of changes in the modulation of VP activity by $\mu$-opioid receptors, evidenced by the decreased effect of locally applied morphine on VP neurons. Decreased pCREB may also be reflective of the reduced capacity of VP neurons to buffer the consequences of excessive glutamatergic transmission.

The physiological relevance of these cellular findings, and how these changes are reflected in the motor sensitization seen in the current study, is of interest. A majority of the VP neurons provide GABAergic projections that target brain regions involved in motor behaviors (eg the subthalamic nucleus, the medial dorsal thalamus, midbrain DA neurons, and the mesencephalic locomotor region/pedunculopontine nucleus; Mogenson et al, 1993). A disinhibition of these targets may contribute to the motor sensitization observed in the present study. As some of these brain regions also regulate reward (eg pedunculopontine nucleus, DA neurons), it is possible that similar mechanisms may contribute to the involvement of the VP in reward-motivated behaviors that occurs with repeated exposure to opiates (Johnson et al, 1993; Caille and Parsons, 2004).

\section{ACKNOWLEDGEMENTS}

We thank Fei Shen for her help in obtaining electrophysiological data for this study. This study was supported by the Ralph and Marian Falk Medical Research Trust (JM and $\mathrm{TCN}$ ) and the Irene Whitney Foundation through the Neuroscience \& Aging Institute Loyola University Chicago (TCN), and USPHSGs DA05255 and DA015760 (TCN).

\section{REFERENCES}

Andersson M, Konradi C, Cenci MA (2001). cAMP response element-binding protein is required for dopamine-dependent gene expression in the intact but not the dopamine-denervated striatum. J Neurosci 21: 9930-9943.

Babbini M, Davis WM (1972). Time-dose relationships for locomotor activity effects of morphine after acute or repeated treatment. Br J Pharmacol 46: 213-224.

Bartoletti M, Gaiardi M, Gubellini G, Bacchi A, Babbini M (1983). Long-term sensitization to the excitatory effects of morphine. A motility study in post-dependent rats. Neuropharmacology 22: 1193-1196.

Bonci A, Williams JT (1997). Increased probability of GABA release during withdrawal from morphine. J Neurosci 17: 796-803.

Bradford MM (1976). A rapid and sensitive method for the quantification of microgram quantities of protein utilizing the principle of protein-dye binding. Anal Biochem 72: 248-254.

Bunney BS, Grace AA (1978). Acute and chronic haloperidol treatment: comparison of effects on nigral dopaminergic cell activity. Life Sci 23: 1715-1727.

Cadoni C, Di Chiara G (1999). Reciprocal changes in dopamine responsiveness in the nucleus accumbens shell and core and in the dorsal caudate-putamen in rats sensitized to morphine. Neuroscience 90: 447-455.

Caille S, Parsons LH (2004). Intravenous heroin self-administration decreases GABA efflux in the ventral pallidum: an in vivo microdialysis study in rats. Eur J Neurosci 20: 593-596.

Chartoff EH, Papadopoulou M, Konradi C, Carlezon Jr WA (2003). Dopamine-dependent increases in phosphorylation of cAMP response element binding protein (CREB) during precipitated morphine withdrawal in primary cultures of rat striatum. $J$ Neurochem 87: 107-118. 
Chrivia JC, Kwok RP, Lamb N, Hagiwara M, Montminy MR, Goodman RH (1993). Phosphorylated CREB binds specifically to the nuclear protein CBP 65. Nature 365: 855-859.

Chrobak JJ, Napier TC (1993). Opioid and GABA modulation of accumbens-evoked ventral pallidal activity. J Neural Trans 93: 123-143.

Garcia MM, Gilster J, Harlan RE (1996). Chronic morphine decreases calbindin D28k immunoreactivity in a subset of cerebellar Purkinje neurons of rat brain. Brain Res 734: 123-134.

Gong W, Neill DB, Lynn M, Justice Jr JB (1999). Dopamine D1/D2 agonists injected into nucleus accumbens and ventral pallidum differentially affect locomotor activity depending on site. Neuroscience 93: 1349-1358.

Gonzalez GA, Yamamoto KK, Fischer WH, Karr D, Menzel P, Biggs III W et al (1989). A cluster of phosphorylation sites on the cyclic AMP-regulated nuclear factor CREB predicted by its sequence. Nature 337: 749-752.

Grace AA, Bunney BS (1986). Induction of depolarization block in midbrain dopamine neurons by repeated administration of haloperidol: analysis using in vivo intracellular recording. J Pharmacol Exp Ther 238: 1092-1100.

Groenewegen HJ, Russchen FT (1984). Organization of the efferent projections of the nucleus accumbens to pallidal, hypothalamic, and mesencephalic structures: a tracing and immunohistochemical study in the cat. J Comp Neurol 223: 347-367.

Guitart X, Thompson MA, Mirante CK, Greenberg ME, Nestler EJ (1992). Regulation of cyclic AMP response element-binding protein (CREB) phosphorylation by acute and chronic morphine in the rat locus coeruleus. J Neurochem 58: 1168-1171.

Heidenreich BA, Mitrovic I, Battaglia G, Napier TC (2004). Limbic pallidal adaptations following long-term cessation of dopaminergic transmission: lack of upregulation of dopamine receptor function. Exp Neurol 186: 145-157.

Henry DJ, Wise RA, Rompré P-P, White FJ (1992). Acute depolarization block of A10 dopamine neurons: interactions of morphine with dopamine antagonists. Brain Res 596: 231-237.

Hicks TP (1984). The history and development of microiontophoresis in experimental neurobiology. Prog Neurobiol 22: 185-240.

Ho N, Liauw JA, Blaeser F, Wei F, Hanissian S, Muglia LM et al (2000). Impaired synaptic plasticity and cAMP response element-binding protein activation in $\mathrm{Ca}^{2+} /$ calmodulin-dependent protein kinase type IV/Gr-deficient mice. J Neurosci 20: 6459-6472.

Hoffman DC, West TEG, Wise RA (1991). Ventral pallidal microinjections of receptor-selective opioid agonists produce differential effects on circling and locomotor activity in rats. Brain Res 550: 205-212.

Johnson PI, Napier TC (1997a). GABA- and glutamate-evoked responses in the rat ventral pallidum are modulated by dopamine. Eur J Neurosci 9: 1397-1406.

Johnson PI, Napier TC (1997b). Morphine modulation of GABAand glutamate-induced changes of ventral pallidal neuronal activity. Neuroscience 77: 187-197.

Johnson PI, Napier TC (2000). Ventral pallidal injections of a mu antagonist block the development of behavioral sensitization to systemic morphine. Synapse 38: 61-70.

Johnson PI, Stellar JR, Paul AD (1993). Regional reward differences within the ventral pallidum are revealed by microinjections of a mu opiate receptor agonist. Neuropharmacology 32: 1305-1314.

Kelz MB, Chen J, Carlezon Jr WA, Whisler K, Gilden L, Beckmann $\mathrm{AM}$ et al (1999). Expression of the transcription factor deltaFosB in the brain controls sensitivity to cocaine. Nature 401: 272-276.

Konradi C, Cole RL, Heckers S, Hyman SE (1994). Amphetamine regulates gene expression in rat striatum via transcription factor CREB. J Neurosci 14: 5623-5634.

Kretschmer BD (2000). Functional aspects of the ventral pallidum. Amino Acids 19: 201-210.
Lahti RA, Mickelson MM, Jodelis KS, McCall JM (1989). Comparative neuroanatomical distribution of the kappa and $M v$-opioid receptors in guinea pig brain sections. Eur $J$ Pharmacol 166: 563-566.

Maidment NT, Brumbaugh DR, Rudolph VD, Erdelyi E, Evans CJ (1989). Microdialysis of extracellular endogenous opioid peptides from rat brain in vivo. Neuroscience 33: 549-557.

Martin G, Ahmed SH, Blank T, Spiess J, Koob GF, Siggins GR (1999). Chronic morphine treatment alters NMDA receptormediated synaptic transmission in the nucleus accumbens. J Neurosci 19: 9081-9089.

Matthews RT, German DC (1984). Electrophysiological evidence for excitation of rat ventral tegmental area dopamine neurons by morphine. Neuroscience 11: 617-625.

McClung CA, Ulery PG, Perrotti LI, Zachariou V, Berton O, Nestler EJ (2004). DeltaFosB: a molecular switch for long-term adaptation in the brain. Brain Res Mol Brain Res 132: 146-154.

Mitrovic I, Napier TC (1996). Interactions between the $m u$ opioid agonist DAMGO and substance $\mathrm{P}$ in regulation of the ventral pallidum. Synapse 23: 142-151.

Mogenson GJ, Brudzynski SM, Wu M, Yang CR, Yim CCY et al (1993). From motivation to action: a review of dopaminergic regulation of limbic-nucleus accumbens-ventral pallidumpedunculopontine nucleus circuitries involved in limbic-motor integration. In: Kalivas PW, Barnes CD (eds). Limbic Motor Circuits and Neuropsychiatry. CRC Press: Ann Arbor. pp 193-225.

Mogenson GJ, Wu M (1986). Subpallidal projections to the mesencephalic locomotor region investigated with a combination of behavioral and electrophysiological recording techniques. Brain Res Bull 16: 383-390.

Montminy MR, Bilezikjian LM (1987). Binding of a nuclear protein to the cyclic-AMP response element of the somatostatin gene. Nature 328: 175-178.

Napier TC (1992). Dopamine receptors in the ventral pallidum regulate circling induced by opioids injected into the ventral pallidum. Neuropharmacology 31: 1127-1136.

Napier TC (1993). Transmitter actions and interactions on pallidal neuronal function. In: Kalivas PW, Barnes CD (eds). Limbic Motor Circuits and Neuropsychiatry. CRC Press: Boca Raton. pp 125-153.

Napier TC, Chrobak JJ (1992). Evaluations of ventral pallidal dopamine receptor activation in behaving rats. NeuroReport 3: 609-611.

Napier TC, Maslowski RJ (1994). Electrophysiological verification for the presence of D1 and D2 dopamine receptors within the ventral pallidum. Synapse 17: 160-166.

Napier TC, Simson PE, Givens BS (1991). Dopamine electrophysiology of ventral pallidal/substantia innominata neurons: comparison with the dorsal globus pallidus. J Pharmacol Exp Ther 258: 249-262.

Narita M, Mizuo K, Shibasaki M, Narita M, Suzuki T (2002). Upregulation of the $\mathrm{G}(\mathrm{q} / 11 \mathrm{alpha})$ protein and protein kinase $\mathrm{C}$ during the development of sensitization to morphine-induced hyperlocomotion. Neuroscience 111: 127-132.

North RA (1993). Opioid actions on membrane ion channels. In: Herz A (ed). Handbook of Experimental Pharmacology. Springer-Verlag: Berlin. pp 773-797.

Nye HE, Hope BT, Kelz MB, Iadarola M, Nestler EJ (1995). Pharmacological studies of the regulation of chronic FOS-related antigen induction by cocaine in the striatum and nucleus accumbens. J Pharmacol Exp Ther 275: 1671-1680.

Nye HE, Nestler EJ (1996). Induction of chronic Fos-related antigens in rat brain by chronic morphine administration. Mol Pharmacol 49: 636-645.

Olive MF, Anton B, Micevych P, Evans CJ, Maidment NT (1997). Presynaptic versus postsynaptic localization of $\mathrm{mu}$ and delta 
opioid receptors in dorsal and ventral striatopallidal pathways. J Neurosci 17: 7471-7479.

Paxinos G, Watson C (1998). The Rat Brain in Stereotaxic Coordinates. Academic Press: New York.

Rhim H, Miller RJ (1994). Opioid receptors modulate diverse types of calcium channels in the nucleus tractus solitarius of the rat. J Neurosci 14: 7608-7615.

Ribar TJ, Rodriguiz RM, Khiroug L, Wetsel WC, Augustine GJ, Means AR (2000). Cerebellar defects in $\mathrm{Ca}^{2+} /$ calmodulin kinase IV-deficient mice. J Neurosci 20: RC107.

Robinson TE, Berridge KC (1993). The neural basis of drug craving: an incentive-sensitization theory of addiction. Brain Res Rev 18: 247-291.

Shreve PE, Uretsky NJ (1989). AMPA, kainic acid, and N-methyl-Daspartic acid stimulate locomotor activity after injection into the substantia innominata/lateral preoptic area. Pharmacol Biochem Behav 34: 101-106.

Stewart J, Badiani A (1993). Tolerance and sensitization to the behavioral effects of drugs. Behav Pharmacol 4: 289-312.

Swanson LW, Mogenson GJ, Gergen GR, Robinson P (1984). Evidence for a projection from the lateral preoptic area and substantia innominata to the 'mesencephalic locomotor region' in the rat. Brain Res 295: 161-178.

Tjon GH, De Vries TJ, Ronken E, Hogenboom F, Wardeh G, Mulder AH et al (1994). Repeated and chronic morphine administration causes differential long-lasting changes in dopaminergic neurotransmission in rat striatum without changing its delta- and kappa-opioid receptor regulation. Eur $J$ Pharmacol 252: 205-212.

Turgeon SM, Pollack AE, Fink JS (1997). Enhanced CREB phosphorylation and changes in c-Fos and FRA expression in striatum accompany amphetamine sensitization. Brain Res 749: $120-126$.

Turner MS, Lavin A, Grace AA, Napier TC (2001). Regulation of limbic information outflow by the subthalamic nucleus: excitatory amino acid projections to the ventral pallidum. J Neurosci 21: 2820-2832.

Turner MS, Mignon L, Napier TC (2002). Alterations in responses of ventral pallidal neurons to excitatory amino acids after long-term dopamine depletion. J Pharmacol Exp Ther 301: 371-381.
Vasko MR, Domino EF (1978). Tolerance development to the biphasic effects of morphine on locomotor activity and brain acetylcholine in the rat. J Pharmacol Exp Ther 207: 848-858.

Vigano D, Rubino T, Di Chiara G, Ascari I, Massi P, Parolaro D (2003). Mu opioid receptor signaling in morphine sensitization. Neuroscience 117: 921-929.

Walters CL, Blendy JA (2001). Different requirements for cAMP response element binding protein in positive and negative reinforcing properties of drugs of abuse. J Neurosci 21: 94389444.

Walters CL, Kuo YC, Blendy JA (2003). Differential distribution of CREB in the mosolimbie dopamine reward pathway. J Neurochem 87: 1237-1244.

Walters CL, Godfrey M, Li X, Blendy JA (2005). Alterations in morphine-induced reward, locomotor activity, and thermoregulation in CREB-deficient mice. Brain Res 1032: 193-199.

Wang L, Gintzler AR (1994). Bimodal opioid regulation of cyclic AMP formation: implications for positive and negative coupling of opiate receptors to adenylyl cyclase. J Neurochem 63: $1726-1730$.

Widnell KL, Russell DS, Nestler EJ (1994). Regulation of expression of cAMP response element-binding protein in the locus coeruleus in vivo and in a locus coeruleus-like cell line in vitro. Proc Natl Acad Sci USA 91: 10947-10951.

Widnell KL, Self DW, Lane SB, Russell DS, Vaidya VA, Miserendino MJD et al (1996). Regulation of CREB expression: in vivo evidence for a functional role in morphine action in the nucleus accumbens. J Pharmacol Exp Ther 276: 306-315.

Wimpey TL, Chavkin C (1991). Opioids activate both an inward rectifier and a novel voltage-gated potassium conductance in the hippocampal formation. Neuron 6: 281-289.

You ZB, Chen YQ, Wise RA (2001). Dopamine and glutamate release in the nucleus accumbens and ventral tegmental area of rat following lateral hypothalamic self-stimulation. Neuroscience 107: 629-639.

Zahm DS, Grosu S, Irving JC, Williams EA (2003). Discrimination of striatopallidum and extended amygdala in the rat: a role for parvalbumin immunoreactive neurons? Brain Res 978: 141-154. 